\title{
Chiropractic Student Perspectives on The Use of Virtual Radiography Simulation An Observational Study Reporting on Chiropractic Students' Perception on The Use of Virtual Radiography as A Clinical Learning Tool
}

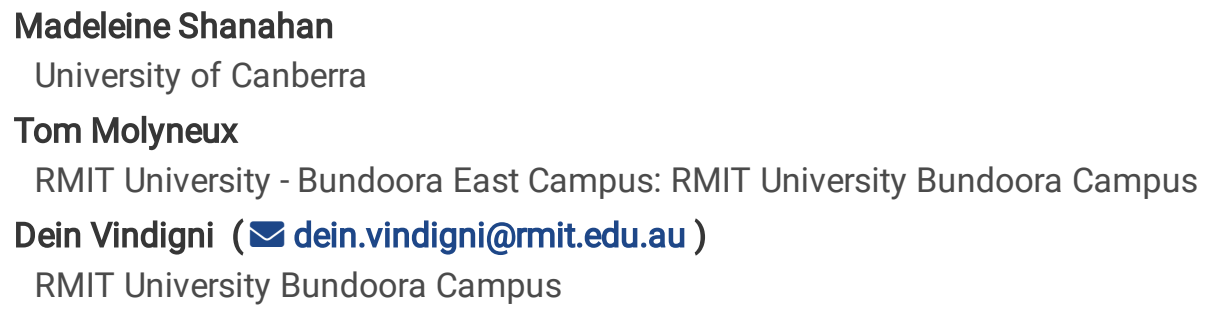

Research article

Keywords: Chiropractors, Radiography, Simulation

Posted Date: October 9th, 2020

DOI: https://doi.org/10.21203/rs.3.rs-87469/v1

License: (9) This work is licensed under a Creative Commons Attribution 4.0 International License. Read Full License

Version of Record: A version of this preprint was published at BMC Medical Education on July 28th, 2021. See the published version at https://doi.org/10.1186/s12909-021-02827-0. 


\section{Abstract}

Background Virtual radiography provides students with an opportunity to practise their clinical skills in patient positioning and evaluating radiographic images. The purpose of this pilot study was to introduce Projection VR ${ }^{\mathrm{TM}}$, a software radiography simulation program, into a student chiropractic program and evaluate its potential application as a teaching and learning tool.

Methods Undergraduate chiropractic students, enrolled in a radiographic course (unit within the chiropractic program), were invited to attend a scheduled laboratory where they were introduced to, and undertook purposefully designed activities using the radiography simulation. At the end of this activity, students were asked to complete an online survey to describe their perceptions of the educational value of the software program. Descriptive and inferential statistics were used to evaluate outcomes.

Results Responses were received from 44 out of the 47 students who attended the scheduled laboratory (response rate $92 \%$ ). Overall students were positive about this simulation identifying that it was easy to use (95\%) and that they could control the equipment as needed (95\%). The main reported benefits included students being enabled to repeat tasks until they were satisfied with the results (98\%) and being able to quickly assess images and determine if changes needed to be made (98\%). Participants reported improvement in their understanding of the effect of exposure factors on patient radiation dose (93\%) as well as their technical image evaluation (84\%) and problem-solving skills (80\%).

Conclusions The results of this study suggest that virtual radiography is a valuable complementary resource in providing chiropractic students with radiographic knowledge and skills.

\section{Background}

Radiography has been integrated into chiropractic teaching programs since 1910 when B.J. Palmer purchased an x-ray unit for the Palmer School of Chiropractic in Davenport, lowa [1]. It has been used as a diagnostic tool in the biomechanical evaluation of the spine and pelvis and to help identify contraindications to manual therapy.

It continues to be taught as a core course in all chiropractic programs in Australia and most chiropractic programs throughout the world [2-4].

Maintaining the quality of imaging whilst minimising the radiation dose to patients is a priority which is highlighted by the Australian Radiation Protection and Nuclear Safety Agency [5] and one which is emphasised in clinical radiographic training and radiology courses (MEDS2144 Introduction to Diagnostic Imaging, MEDS2143 Advanced Diagnostic Imaging and REHA2203 Chiropractic 6 Theory) at RMIT University [6].

The opportunity to participate in simulated radiography is complementary to rigorous training in the theoretical and clinical aspects of plain film diagnostic imaging.

In recent years, computer-based simulation radiography has been introduced in undergraduate radiography programs with promising results $[7,8]$.However, its usefulness in achieving clinical learning outcomes in pre-clinical undergraduate chiropractic programs has not been previously evaluated.

This study aimed to introduce a software radiography simulation tool called Projection VR ${ }^{\mathrm{TM}}$ into a chiropractic, pre-clinical undergraduate setting and gather student feedback about its application as a clinical learning tool and strategy.

\section{Methods}

The Human Research Ethics Committee of the Royal Melbourne Institute of Technology (RMIT) University (BSEHAPP 06-15) approved the project, including its design and recruitment methods.

\section{Participants:}


Chiropractic students in the second semester of year four of the program in 2016 were recruited as part of their traditional practical sessions in radiography. Informed consent was obtained in the first test item of an online survey, with respondents able to exit at this point if they so preferred.

\section{Procedure:}

Participating chiropractic students were scheduled to attend one laboratory session which used the computer-based virtual radiography simulation software Projection VR ${ }^{\mathrm{TM}}$. Projection $\mathrm{VR}^{\mathrm{TM}}$ simulation in this university setting could be adequately delivered via Windows 8 or 7 (64 or 32 bit) with a graphics processor of at least DirectX and Shader Model 3.0 or 4.0 hardware support and 512 megabytes or more of dedicated video RAM. The standard computer laboratory equipment at the university met or exceeded these requirements.

A worksheet on simulated radiography of the lumbar spine was developed for chiropractic students using Projection VR ${ }^{T M}$. No training was conducted prior to using the simulated radiography system as students learned to use the technology while they undertook the activity under the guidance of an experienced lecturer in radiography. The detailed worksheet allowed the students to use the technology as they undertook the laboratory activity. Each student used the simulation individually.

There were three key areas of focus for this activity. Firstly, for each student to simulate patient positioning and technical set up in preparation for taking the Anterior to Posterior lumbopelvic image and to generate an AP lumbopelvic (APLP) image (Figure 1). Secondly, having produced an unrotated APLP, students were then asked to rotate their patient so that the patient's right posterior side was closer to the image receptor (Figure 2). Before generating the image, students were asked what distinguishing anatomical features they expected to see on the image (Figure 2). This strategy was used to support active and engage critical thinking as students consciously paused and reflected before they undertook their next action [9]. Thirdly, the effect of exposure factor selection on the digital image as well as patient dose was investigated. This was tested using two methods, namely application of the $15 \%$ rule and the effect of decreasing and increasing milliamp seconds (mAs) on digital images. Increasing kilo volt peak $(\mathrm{kVp})$ with a concomitant decrease in $\mathrm{mAs}$ is expressed as the $15 \% \mathrm{kVp}$ rule. The $15 \%$ rule states that a $15 \%$ increase in $\mathrm{kVp}$ is the equivalent of doubling the exposure received at the image receptor [10,11]. To maintain exposure at the image receptor, the $\mathrm{mAs}$ is halved. The increase in $\mathrm{kVp}$, when applying the $15 \%$ rule, is variable and dependent on the original $\mathrm{kVp}$. For example, at $60 \mathrm{kVp}$, the calculated change in $\mathrm{kVp}$ is be $9 \mathrm{kVp}$ whereas at $80 \mathrm{kVp}$, the required change is $12 \mathrm{kVp}$. Studies examining application of the $15 \% \mathrm{kVp}$ rule demonstrate a considerable reduction in patient dose $(22 \%-60 \%)$ without adversely affecting image quality $[12,13]$. This is an important finding as increasing $k V p$ reduces subject contrast and could therefore potentially negatively impact image quality $[10,11]$. Before generating the image acquired using the $15 \%$ rule, students were asked what change if any they may expect to see on the image (Figure 3) and what impact, if any, applying the $15 \%$ rule would have on patient dose. Technical data available in Projection VR ${ }^{\mathrm{TM}}$ relating to radiation dose for the two images generated is provided in Figure 4. Entrance surface dose (ESD) measurements were compared for the two exposure techniques. The final aspect of selection of exposure factors on digital images was undertaken by asking students what difference they would expect to see on the radiographic image and on patient dose if they were to half or double the mAs. Generated images are provided in Figure 5 .

Throughout the session, students were asked to predict the outcome of each change in patient position or exposure factors before they generated and saw images or technical data. This method was used to encourage students to think critically in applying their decision-making skills in a clinical setting and has been found to reinforce learning by other authors $[9,14,15]$.

\section{Evaluation of virtual radiography}

Students who were enrolled in the radiographic positioning course in the chiropractic program were invited to participate anonymously in an online Qualtrics survey during the session. The survey comprised a mix of quantitative and qualitative items including Likert scales and open-ended questions. This assessed the ease with which students used Projection $\mathrm{VR}^{\mathrm{TM}}$ and the extent to which they developed program skills. Survey data were then entered for analysis.

\section{Data Analysis:}


The survey data were entered into SPSS $21.0 \AA$ and descriptive and inferential statistics were used for analysis. Cross tabulations were performed using age group and gender and self-reported confidence using computer technology to determine if relationships existed. Differences between groups were examined using chi-square analysis and Fisher's exact test.

Analysis of survey data was descriptive only as this research involved an exploratory snap-shot process - that is, the survey was only administered once [16] .

\section{Results}

Responses were received from 44 out of 47 participants in the practical sessions. The gender and age characteristics of the responding students are presented in Table 1.

Table 1

Demographic characteristics of survey respondents $(n=44)$

\begin{tabular}{|c|c|c|}
\hline Characteristic & & Number (\%) \\
\hline \multirow[t]{2}{*}{ Gender } & Female & $30(68)$ \\
\hline & Male & $14(32)$ \\
\hline \multirow[t]{4}{*}{ Age (years) } & $18-21$ & $22(50)$ \\
\hline & $22-25$ & $11(25)$ \\
\hline & $26-29$ & $4(9)$ \\
\hline & $30+$ & $7(16)$ \\
\hline
\end{tabular}

The majority of students were female $(68 \%)(M=14, F=30)$. All age groups were represented in this sample and included both high school leavers and mature aged students.

\section{Technology}

Given that Projection VR ${ }^{T M}$ involves computer-based simulation, participants were asked about their confidence in using this technology as part of their learning strategy. Eighty-two\% $(n=36)$ of responding participants described themselves as confident or moderately confident in the use of computer technology. Only $18 \%$ (eight students) reported that they had previous experience using computer-based simulation. No relationship was shown to exist $(p>.05)$ between gender or age and students' perception of their confidence in the use of computer technology.

Students' perceptions of ease of use of Projection VR ${ }^{\mathrm{TM}}$ are summarised in Table 2.

Table 2

Student perceptions ease of use of Projection VR ${ }^{\text {TM }}(n=44)$

\begin{tabular}{|lllllll|}
\hline Question & $\begin{array}{l}\text { Strongly } \\
\text { agree }\end{array}$ & Agree & $\begin{array}{l}\text { Neither agree } \\
\text { nor disagree }\end{array}$ & $\begin{array}{l}\text { Dis- } \\
\text { agree }\end{array}$ & $\begin{array}{l}\text { Strongly } \\
\text { disagree }\end{array}$ & $\begin{array}{l}\text { Total } \\
\text { Number }\end{array}$ \\
\hline Projection VR & 8 & 34 & 2 & 0 & 0 & 44 \\
\hline $\begin{array}{l}\text { I could control the equipment as I needed when to use } \\
\text { using Projection VR }\end{array}$ & 15 & 27 & 2 & 0 & 0 & 44 \\
\hline $\begin{array}{l}\text { I liked using Projection VR } \\
\text { TM }\end{array}$ & 17 & 22 & 4 & 1 & 0 & 44 \\
\hline $\begin{array}{l}\text { Technical problems made using Projection VR } \\
\text { difficult }\end{array}$ & 4 & 6 & 11 & 14 & 9 & 44 \\
\hline $\begin{array}{l}\text { The Projection VR } \\
\text { easy to follow }\end{array}$ & 7 & 27 & 7 & 0 & 1 & 44 \\
\hline
\end{tabular}


Overall, students were positive regarding ease of use of the simulation software and their ability to control the equipment during the learning activity. Some students commented that the simulation could be improved by making it easier to use, with one student specifying "some of the keys made it hard to set up accurately".

Chiropractic students' perceptions of use of Projection VR ${ }^{T M}$ as a learning tool for radiography is displayed in Table 3.

Table 3

Student perceptions on Projection VR ${ }^{\mathrm{TM}}$ as a learning tool for radiography $(\mathrm{n}=44)$

\begin{tabular}{|c|c|c|c|c|c|c|}
\hline $\begin{array}{l}\text { Question } \\
\text { Using Projection VR }\end{array}$ & $\begin{array}{l}\text { Strongly } \\
\text { agree }\end{array}$ & Agree & $\begin{array}{l}\text { Neither agree } \\
\text { nor disagree }\end{array}$ & $\begin{array}{l}\text { Dis- } \\
\text { agree }\end{array}$ & $\begin{array}{l}\text { Strongly } \\
\text { disagree }\end{array}$ & $\begin{array}{l}\text { Total } \\
\text { Number }\end{array}$ \\
\hline $\begin{array}{l}\text { Encouraged me to think more about radiographic } \\
\text { procedures }\end{array}$ & 17 & 22 & 3 & 2 & 0 & 44 \\
\hline $\begin{array}{l}\text { Had a positive effect on my ability to set up a } \\
\text { radiographic examination }\end{array}$ & 15 & 17 & 8 & 3 & 1 & 44 \\
\hline $\begin{array}{l}\text { Allowed me to quickly see images and understand if } \\
\text { changes needed to be made }\end{array}$ & 25 & 18 & 1 & 0 & 0 & 44 \\
\hline $\begin{array}{l}\text { Had a positive effect on my ability to evaluate } \\
\text { radiographic images }\end{array}$ & 17 & 20 & 7 & 0 & 0 & 44 \\
\hline $\begin{array}{l}\text { Helped me learn as I was able to repeat activities until } \\
\text { I was satisfied with the results }\end{array}$ & 21 & 22 & 1 & 0 & 0 & 44 \\
\hline Encouraged me to solve problems & 12 & 23 & 8 & 1 & 0 & 44 \\
\hline $\begin{array}{l}\text { Had a positive effect on my confidence level in setting } \\
\text { up radiographic examinations }\end{array}$ & 11 & 23 & 8 & 2 & 0 & 44 \\
\hline $\begin{array}{l}\text { Had a positive effect on my confidence level in } \\
\text { evaluating radiographic images }\end{array}$ & 9 & 26 & 7 & 2 & 0 & 44 \\
\hline $\begin{array}{l}\text { Encouraged me to think more about evaluating } \\
\text { radiographic images }\end{array}$ & 20 & 20 & 4 & 0 & 0 & 44 \\
\hline $\begin{array}{l}\text { Helped me understand the effect of changing } \\
\text { radiographic exposure factors on patient dose }\end{array}$ & 19 & 22 & 2 & 1 & 0 & 44 \\
\hline Projection VR is a valuable part of the laboratory & 19 & 19 & 5 & 1 & 0 & 44 \\
\hline $\begin{array}{l}\text { Projection VR complements other learning activities in } \\
\text { the laboratory }\end{array}$ & 19 & 21 & 2 & 2 & 0 & 44 \\
\hline $\begin{array}{l}\text { Projection VR should continue to be used in the } \\
\text { laboratory }\end{array}$ & 21 & 19 & 3 & 1 & 0 & 44 \\
\hline
\end{tabular}

Students generally perceived Projection VR ${ }^{\mathrm{TM}}$ as a worthwhile educational tool that quickly generated radiographic images and enabled them to refine the process until they were confident in its application. Student comments described benefits of using the simulation including "Easy and quick visualisation of an x-ray image", "It was a good simulation to be able to see what we're actually imaging" and "you can visualise anything you want to, at whatever angle you want to. Very helpful especially for visual learners like myself".

Students also reported that using the program encouraged them to think more about radiographic technique and it facilitated their problem-solving skills. Student comments included "made me think about what I was doing", "helped me to think wisely on how the image should be produced" and "enabled me to produce images and see where I needed to correct myself to get a better image".

In addition, students identified that the simulation activity enhanced their understanding of technical factor selection and radiation dose. For example, students stated that using the simulation "helped me to understand the exposure", "helped me understand the technical side, not just positioning" and it "gave us extra information on patient dose and levels of radiation". 
Students also perceived the use of this simulation program as enhancing their learning opportunities. Their comments included "it combines the theory and practical context taught during Chiropractic Theory 6 whilst introducing a new way of expanding our skills and knowledge through technology" and "regular practice sessions with the computers would be great to assist the physical learning". Students also recognised that this simulation provided a safe learning environment as it did not require the use of radiation "being able to redo and correct any mistakes without worry".

Students did report limitations of the simulation including that, as movement of $\mathrm{x}$-ray tube was controlled by computer keys, "some buttons are difficult to find" and "some of the keys made it hard to set up accurately". It was also noted that as you are unable to palpate the virtual patient "more bony landmarks on patient" were needed.

\section{Discussion}

The aim of this study was to explore chiropractic students' perceptions of the Projection VR ${ }^{T M}$ to assist in developing their radiographic skills and confidence in a laboratory setting. This study suggested that the simulation did improve students' learning experience.

The Projection VR ${ }^{\mathrm{TM}}$ was previously incorporated into the Medical Imaging program in the School of Health and Biomedical Sciences (SHBS) at RMIT University with most technical complications being resolved by the time the simulation program was trialled with chiropractic students. In general, the program supported students' skill development and enhanced confidence levels. Moreover, gender and age have been reported as possible barriers to using computer technology. In this study, differences in confidence levels were not associated with gender and age.

Another potential application of this program is remote access by students. The advantages of such access include the flexible delivery of learning and teaching, overcoming geographical barriers in terms of travel as well as students being able to acquire skills and knowledge at their own pace [17].

Students in this study identified that remote access to this simulation would be a beneficial change e.g. "simulation of practicals into computers makes practice easier and more accessible", "make it readily available to practise at home" and "use of it at home via RMIT website, lists of views required for exam so we can practice”.

Given that there is variety in the reported levels of confidence, computer skills and abilities among students, the option of their being able to progress through simulation activities at their own pace is likely to facilitate the learning experience.

\section{Confidence and skill development}

In general, the introduction of Projection VR ${ }^{\mathrm{TM}}$ increased students' confidence in patient positioning procedures and their ability to evaluate radiographic images. It has been reported that enhancing students' clinical radiographic skills as they make the transition from their pre-clinical undergraduate education to clinical practice may help to alleviate the stress associated with this transition [18].

Having acquired the skills to confidently set up radiographic procedures and evaluate images, students have reported being able to better focus their energies on refining their communication and patient-interaction skills [19].

Students also described that participating in the Projection VR ${ }^{\mathrm{TM}}$ simulation positively influenced their ability to problem solve. These findings are consistent with other published reports that highlight the value of students critically reflecting on their perceived strengths and weaknesses as a step to solving future clinical challenges and contributing to a range of other important clinical and professional standards [20,21].

Ninety-three percent of students identified that the simulation activity enhanced their understanding of the effect of changing radiographic exposure factors on patient dose. Chiropractors who perform radiography have a responsibility to select exposure parameters which minimise patient dose when producing clinically diagnostic images. Key parameters that a chiropractor controls and can manipulate for radiographic examinations include tube voltage $(\mathrm{kVp})$, tube current and time (mAs) and source 
to image distance (SID). If SID is traditionally fixed at $150 \mathrm{~cm}$ for chiropractic planar imaging [22], then student chiropractors should develop a good understanding of $15 \%$ rule as a radiation dose reduction strategy. Projection $\mathrm{VR}^{\mathrm{TM}}$ simulation provides similar percent dose reduction measurements to direct dosimetry measurements when assessing application of the $15 \%$ rule [23]. Student comments also highlighted the value of using this simulation to better understand technical factor selection for planar radiography "It helped me learn more about the technical side of medical imaging, such as kVp and dosages" and "gave us extra information on patient dose". Projection $\mathrm{VR}^{\mathrm{TM}}$ is a useful educational tool to support student learning focussed on exposure parameters and dose reduction technique in planar radiography. Potential applications of the simulation program within the chiropractic curriculum may include:

a) assist in providing a blended learning approach to teaching radiographic positioning that includes the theoretical basis of radiography in chiropractic practice, face-to-face practicals and virtual radiography to complement and reinforce these more traditional approaches to teaching and learning;

b) help students to better understand how positioning influences radiation exposure (including factors such as skin dose and absorbed dose);

c) provide a cost-effective and efficient mechanism to 'practice' positioning;

d) assist in demonstrating how positioning influences radiographic anatomy;

e) currently none of the four chiropractic programs in Australia incorporate virtual radiography in their curricula and the preliminary findings of this study demonstrate the potential to incorporate virtual chiropractic radiography into their curricula as part of an effective blended learning approach to learning and teaching.

\section{Study limitations}

This study explored the students' perceptions of virtual radiography in the undergraduate pre-clinical radiography course as part of a university chiropractic program.

Previous authors have noted that student performance may be influenced by a variety of factors $[7,19]$ and this interplay of factors may confound the ability to independently evaluate the role of specific potential enablers such as simulated teaching. This is particularly true when an innovative teaching tool or strategy is introduced into a new learning environment [19].

Documenting the student usage patterns of innovative teaching programs such as simulated radiography may also provide valuable information about how to best achieve flexibly delivered, clinical educational programs such as this in the future.

\section{Conclusion}

The Projection VR ${ }^{\mathrm{TM}}$ software was adapted for use in an undergraduate university chiropractic radiography program.

The introduction of this software was associated with multiple benefits including an increase in skills and confidence in students' ability to effectively prepare their patients for radiographic positioning and quality imaging while minimising their exposure to irradiation dose.

The software also promoted their problem-solving skills in preparation for their transition to professional practice.

\section{List Of Abbreviations}

RMIT Royal Melbourne Institute of Technology

SHBS School of Health and Biomedical Sciences

\section{Declarations}




\section{Ethics Approval and Consent to Participate}

The project, including its design and recruitment methods was approved by the Human Research Ethics Committee of the Royal Melbourne Institute of Technology (RMIT) University (BSEHAPP 06-15). Informed consent was implied by completion and submission of the anonymous survey.

\section{Consent for Publication}

All authors have provided their written consent for this manuscript to be published

\section{Availability of data and materials}

The datasets used and/or analysed during the current study are available from the corresponding author on reasonable request.

\section{Competing Interests}

All authors declare they have no competing interests

\section{Funding}

This study was unfunded

\section{Authors Contribution}

Author MS originally developed, delivered and evaluated a virtual radiography program for use by radiography students and collaborated with TM and DV to adapt the radiography teaching tool for chiropractic students. Authors TM and DV helped in constructing variables and questions of particular relevance for chiropractic educators and students. Authors MS, TM and DV each assisted in analysing and interpreting the patient data, writing and editing the manuscript. All authors read and approved the final manuscript.

\section{Acknowledgements}

Thanks to Dr Joe Messina and Mr Bruno Treglia for supervising the students in the radiography lab and to all the chiropractic students who responded to our survey. Also, to Associate Professor Cliff Da Costa for his assistance in the statistical analysis and $\operatorname{Dr}$ Andisheh Bastani for her help in formatting the manuscript.

\section{Authors' Information}

MS School of Health Sciences, University of Canberra. madeleine.shanahan@canberra.edu.au and Adjunct Associate Professor, School of Health and Biomedical Sciences, RMIT University.

TM Discipline of Chiropractic, School of Health and Biomedical Sciences, RMIT University. tom.molymeux@rmit.edu.au DV Discipline of Chiropractic, School of Health and Biomedical Sciences, RMIT University. dein.vindigni@rmit.edu.au

\section{References}

1. Peterson D,Wiese G. Chiropractic: An illustrated history. 1st ed ed. Mosby Incorporated. 1995.

2. The Council on Chiropractic Education. CCE Accreditation Standards 2018 In: Council on Chiropractic Education Australasia. http://www.cce-usa.org/uploads/1/0/6/5/106500339/2018_cce_accreditation_standards.pdf. 24 June 2020.

3. Council on Chiropractic Education Australasia. Chiropractic Accreditation and Competency Standards 2017 In: Council on Chiropractic Education Australasia. 2017. https://www.ccea.com.au/files/1015/0450/1916/CCEA_Accreditation_and_Competency_Standards_2017.pdf. 24 June 2020. 
4. European Council on Chiropractic Education. Accreditation Procedures and Standards. 2018. http://www.cceeurope.com/downloads.html. 24 June 2020.

5. Australian Radiation Protection and Nuclear Safety Agency. Codes and standards applicable to sources. https://www.arpansa.gov.au/regulation-and-licensing/licensing/information-for-licence-holders/licenceconditions/applicable-codes-and-standards. 24 June 2020.

6. RMIT University. BP280 - Bachelor of Health Science/Bachelor of Applied Science (Chiropractic). http://www1.rmit.edu.au/programs/structure/bp280hsddausbu. 24 June 2020.

7. Cosson P,Willis R. Comparison of student radiographers' performance in a real $x$-ray room after training with a screen based computer simulator. 2012. http://www.shaderware.com/distrib/etc/WhitePaper-

ComparisonOfStudentRadiographersPerformancelnaRealXrayRoomAfterTrainingWithAScreenBasedComputerSimulator.pdf. 24 June 2020.

8. Shanahan MJR. Student perspective on using a virtual radiography simulation. 2016. 22: 3. p. 217-222.

9. Rodgers CJTcr. Defining reflection: Another look at John Dewey and reflective thinking. 2002. 104: 4. p. 842-866.

10. Bushong SC. Radiologic science for technologists-E-book: physics, biology, and protection. 10th ed. Elsevier Health Sciences. 2013.

11. Carlton RR,Adler AM. Principles of Radiographic Imaging. 5th ed. Cengage Learning. 2012.

12. Allen E, Hogg P, Ma WK, Szczepura KJR. Fact or fiction: an analysis of the 10 kVp 'rule'in computed radiography. $2013.19: 3$. p. 223-227.

13. Lança L, Franco L, Ahmed A, Harderwijk M, Marti C, Nasir S, et al. 10 kVp rule-an anthropomorphic pelvis phantom imaging study using a CR system: impact on image quality and effective dose using AEC and manual mode. 2014. 20: 4. p. $333-338$.

14. Jonassen DH. Computers as mindtools for schools: Engaging critical thinking. 2nd ed. Prentice hall. 2000.

15. Jonassen DH. Meaningful learning with technology. 3rd edition ed. Upper Saddle River, N.J: Pearson/Merrill Prentice Hall. 2008.

16. Lambert VA,Lambert CEJPRIJoNR. Qualitative descriptive research: An acceptable design. 2012. 16: 4. p. $255-256$.

17. MacDonald-Hill J,Warren-Forward HJR. Feasibility study into the use of online instrumentation courses for medical radiation scientists. 2015. 21: 3. p. 282-287.

18. Mason SLJRT. Radiography student perceptions of clinical stressors. 2006. 77: 6. p. 437-450.

19. Bridge P, Crowe S, Gibson G, Ellemor N, Hargrave C, Carmichael MJR. A virtual radiation therapy workflow training simulation. 2016. 22: 1. p. e59-e63.

20. Kuiper RA,Pesut DJ. Promoting cognitive and metacognitive reflective reasoning skills in nursing practice: self-regulated learning theory. J Journal of advanced nursing. 2004. 45: 4. p. 381-391.

21. Mann K, Gordon J, MacLeod A. Reflection and reflective practice in health professions education: a systematic review. J Advances in health sciences education. 2009. 14: 4. p. 595-621.

22. Yochum TR,Rowe LJ. Essentials of skeletal radiology. 2nd ed. Lippincott Williams \& Wilkins. 1987.

23. Shanahan MJR. A pilot study investigating two dose reduction techniques for AP lumbar spine radiography using direct dosimetry and Projection VR. 2017. 23: 3. p. 222-228.

\section{Figures}



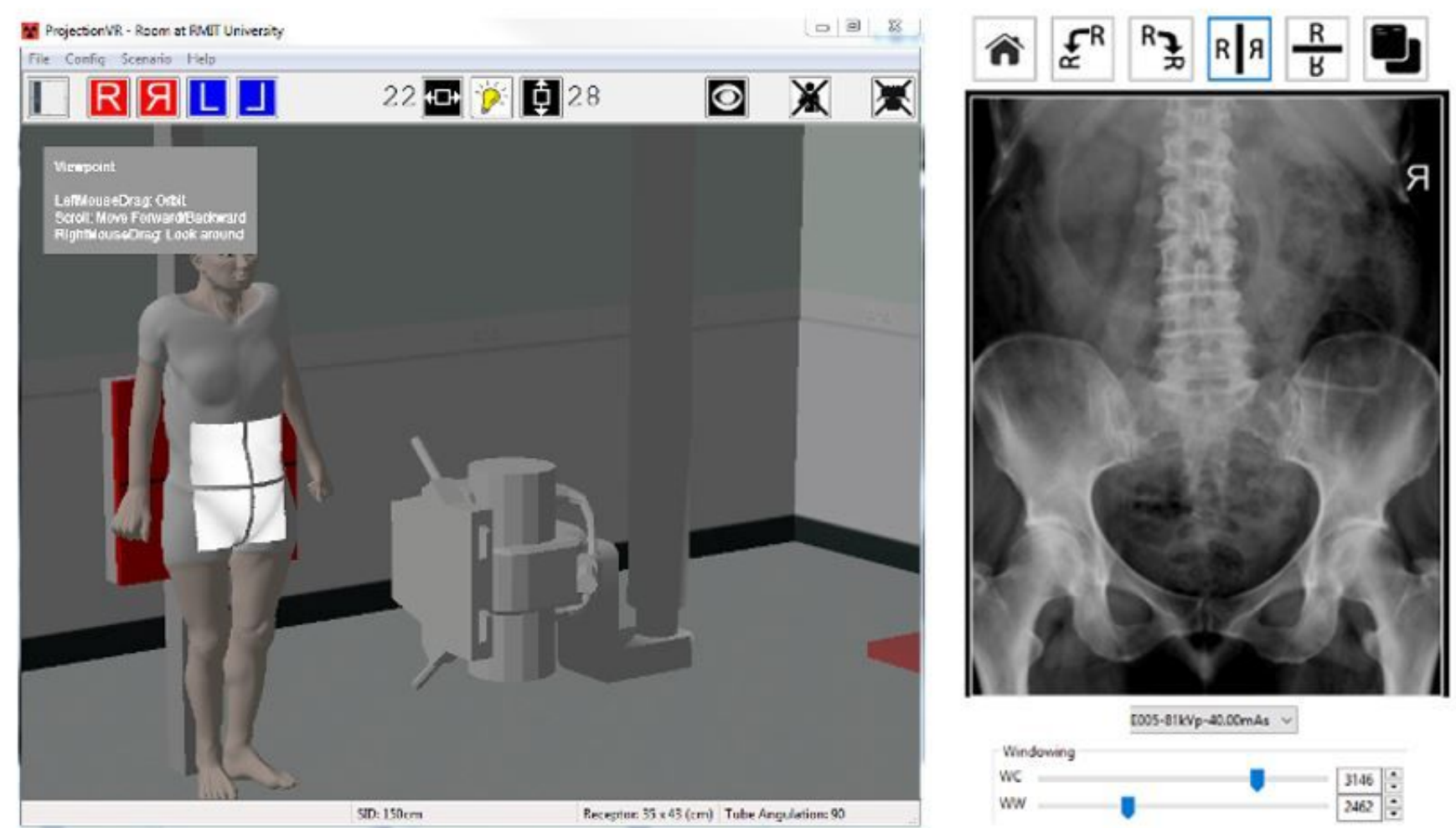

\section{Figure 1}

Technical set up for Anterior to Posterior lumbopelvic (left) and resultant image generated (right) using Projection VR ${ }^{\mathrm{TM}}$
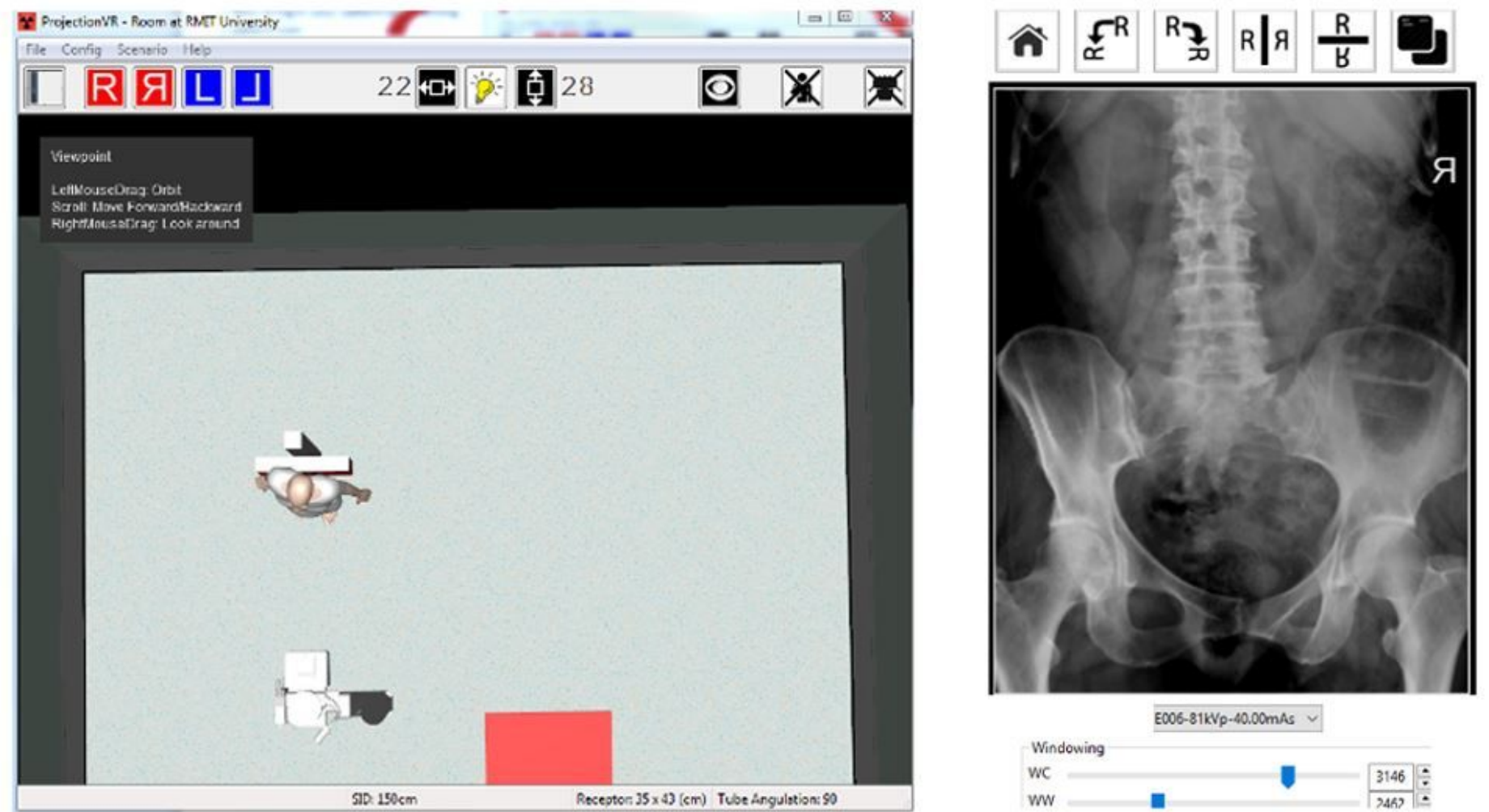

Figure 2 
Technical set up for rotated (Right anterior oblique position) Anterior to Posterior lumbopelvic (left) and resultant image generated (right) using Projection VR ${ }^{\mathrm{Tm}}$

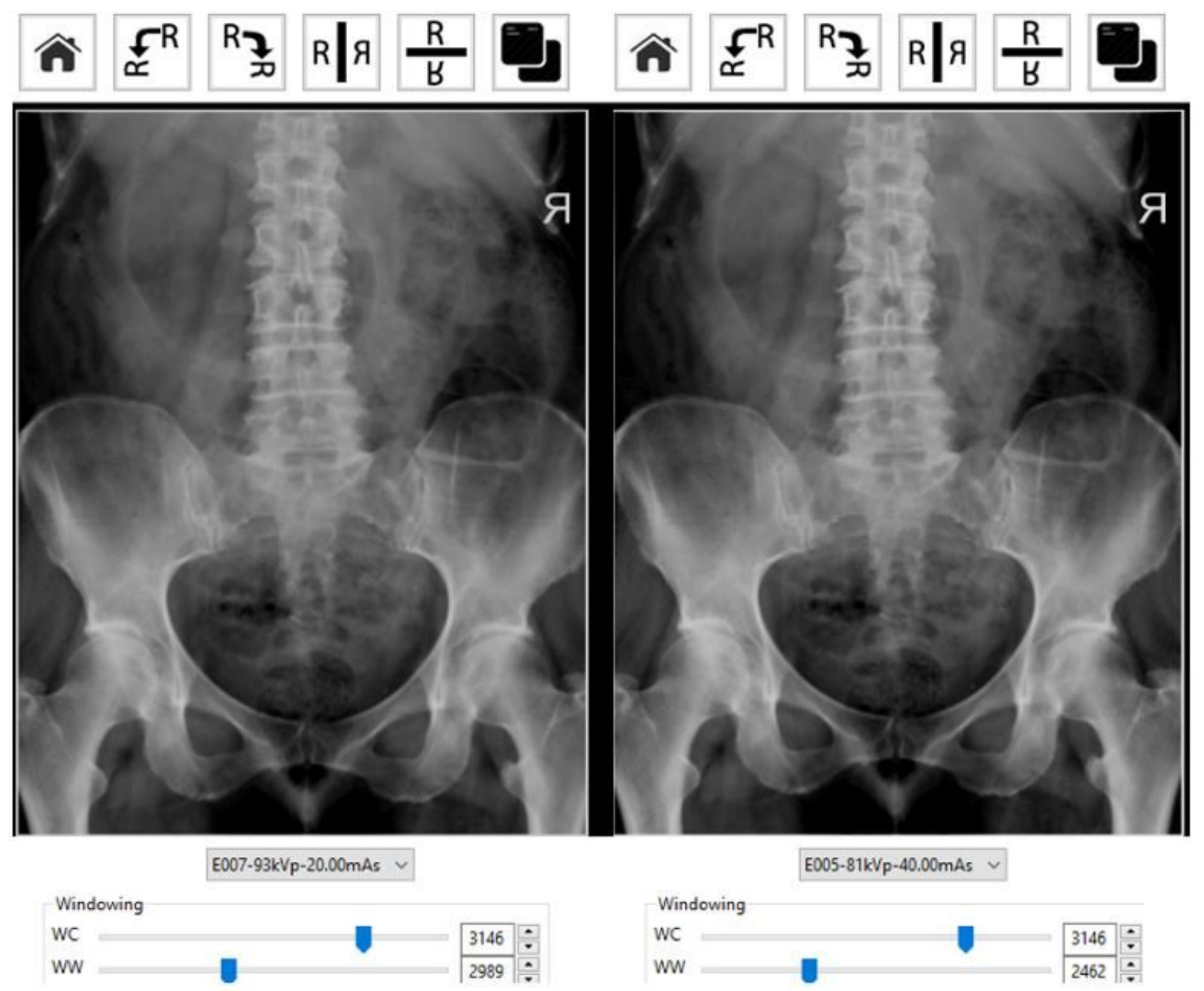

Figure 3

Images generated using Projection VR ${ }^{T M}$ with 15\% rule applied. Image on right 81 kVp, 40 mAs and image on left 93 kVp, 20 mAs. 


E007-93kVp-20.00mAs
- Patient:Bouvier-SwishernPatrici
- Cassette:35CMX43CM
- Tube Voltage: $93 \mathrm{kV}$
- Care Filter: Off $(0.00 \mathrm{~mm} \mathrm{Cu})$
- Tube Charge: $20.00 \mathrm{mAs}$
- SID: $150 \mathrm{~cm}$
- Coll: $22 \mathrm{~cm} \times 28 \mathrm{~cm}$ (@ $100 \mathrm{~cm})$
- Part Thickness (CR): $260 \mathrm{~mm}$
- Part Thickness: $226 \mathrm{~mm}$
- Scatter Rej. Grid: Bucky $12: 1$
- Scatter Fraction: 0.36
- DAP: $158.01 \mathrm{cGy} \mathrm{cm}{ }^{2}$
- Incident Dose: $1.770 \mathrm{mGy}$
- ESD: $2.528 \mathrm{mGy}$
- Sys Dose(ROI): 5.49 uGy
- Sys Dose(CR): 3.47 uGy
- Sys Dose: 4.94 uGy
- El: 672
- Agfa IgM: 2.39
- Kodak P: 1886
- Fuji S: 354
- Fuji L: 1.26

E006-81kVp-40.00mAs

- Patient:Bouvier-Swisher ${ }^{\mathrm{P} P a t r i c i}$

- Cassette:35CMX43CM

- Tube Voltage: $81 \mathrm{kV}$

- Care Filter: Off $(0.00 \mathrm{~mm} \mathrm{Cu})$

- Tube Charge: $40.00 \mathrm{mAs}$

- SID: $150 \mathrm{~cm}$

- Coll: $22 \mathrm{~cm} \times 28 \mathrm{~cm}$ (@ 100cm)

- Part Thickness (CR): $264 \mathrm{~mm}$

- Part Thickness: 229mm

- Scatter Rej. Grid: Bucky 12:1

- Scatter Fraction: 0.34

- DAP: 250.40 cGy cm²

- Incident Dose: 2.798 mGy

- ESD: $3.927 \mathrm{mGy}$

- Sys Dose(ROI): 5.91 uGy

- Sys Dose(CR): 3.11 uGy

- Sys Dose: 5.00 uGy

- El: 579

- Agfa lgM: 2.33

- Kodak P: 1821

- Fuji S: 350

- Fuji L: 1.50

\section{Figure 4}

Technical data display available when using Projection VR ${ }^{\mathrm{TM}}$ allowing for comparison of Entrance Surface Dose (ESD) with $15 \%$ rule applied. Image on right 81 kVp, 40 mAs and image on left 93 kVp, 20 mAs. 


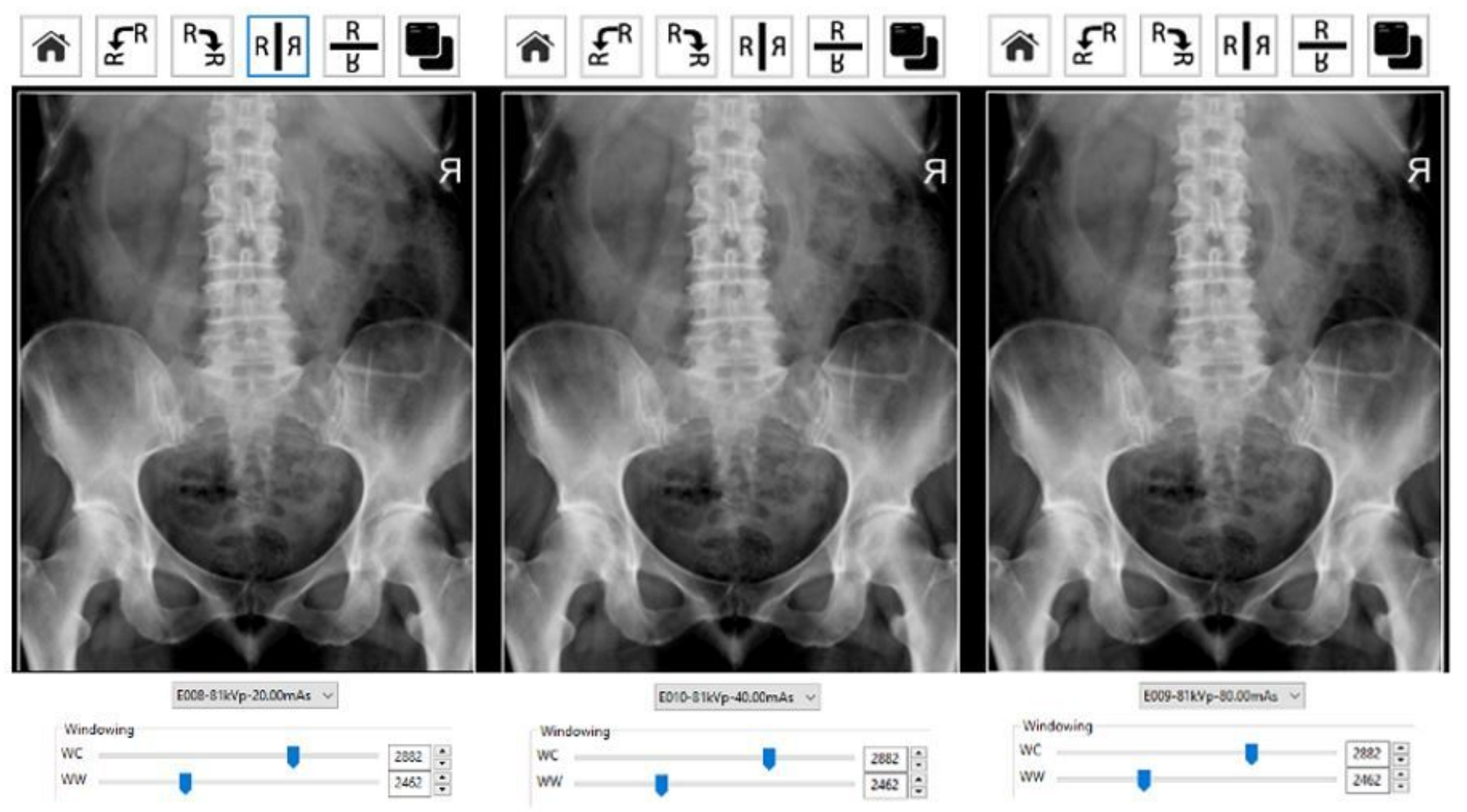

Figure 5

Images generated using Projection VR ${ }^{\mathrm{TM}}$ at $81 \mathrm{kVp}$ and varying mAs 20 mAs (left), 40 mAs (centre) and 80 mAs (right) 